\title{
Reliability and Validity of the Norwegian Family Sense of Coherence Scale
}

\section{Øyfrid Larsen Moen', Marie Louise Hall-Lord ${ }^{1,2}$}

${ }^{1}$ Department of Health Sciences in Gjøvik, Faculty of Medicine and Health Sciences, Care and Nursing, Norwegian University of Science and Technology (NTNU), Gjøvik, Norway

${ }^{2}$ Institution of Health Sciences, Faculty of Health, Nature and Technological Sciences, Karlstad University, Karlstad, Sweden

Email: oeyfrid.moen@ntnu.no

How to cite this paper: Moen, Ø.L. and Hall-Lord, M.L. (2016) Reliability and Validity of the Norwegian Family Sense of Coherence Scale. Open Journal of Nursing, 6, 1075-1086.

http://dx.doi.org/10.4236/ojn.2016.612102

Received: December 7, 2016

Accepted: December 27, 2016

Published: December 30, 2016

Copyright (c) 2016 by authors and Scientific Research Publishing Inc. This work is licensed under the Creative Commons Attribution International License (CC BY 4.0).

http://creativecommons.org/licenses/by/4.0/ c) (i) Open Access

\section{Abstract}

Aims and Objectives: To investigate reliability and validity of the translated Norwegian version of the Family Sense of Coherence scale. Background: The Family Sense of Coherence scale measures the global sense of coherence in families and might help health professionals to identify vulnerable families and to facilitate the strengthening of coping strategies in families. Design: Cross-sectional. Methods: In total, 264 parents of children with Attention Deficit Hyperactivity Disorder (ADHD) and 157 parents of children in secondary schools in three municipalities responded to a questionnaire regarding the characteristics of the parent and the child, with four scales: Family Sense of Coherence, Sense of Coherence, Family Assessment Device and Well-being. Statistics with Cronbach alpha, intra-class correlation coefficient, independent sample t-test and Pearson's correlation coefficient were used to establish the reliability and validity of the scale. Results: Internal consistency with Cronbach's alpha was acceptable and test-retest reliability with intra-class correlation coefficient was sufficient. Known-groups test revealed statistical differences between the two groups of parents as pre-considered and significant correlations between Family Sense of Coherence and Sense of Coherence, Family Assessment Device and Well-being were found. Conclusion: The Norwegian version of Family Sense of Coherence scale can be considered as reliable and valid for the studied population. Relevance to Clinical Practice: The Family Sense of Coherence scale appears to be an appropriate instrument for evaluating and assessing to find vulnerable families who are in need of interventions strengthening the family's resources.

\section{Keywords}

Attention Deficit Hyperactivity Disorder, Family, Instrument Development, Research Methods, Sense of Coherence 


\section{Introduction}

Public health nurses, nurses at schools and community health services play a valuable role in the encounter with- and referral of families with different challenges, disorders or chronic illnesses living in difficult life situations [1]. The nurse will encounter these families with a focus on the child or the entire family's needs.

Salutogenesis refers to the health perspective, in which healthy functioning and people's resources are emphasized instead of the pathogenic perspective where the focus is on what causes illness and disease [2]. Sense of Coherence (SOC) is essential in the salutogenic theory, and consists of the components of comprehensibility, manageability and meaningfulness. Comprehensibility refers to a feeling of confidence, in which one's internal and external environments are structured and predictable, including, for example, information given that is perceived as structured and clear. Manageability refers to the available resources to meet challenges in life, while meaningfulness contains a motivational component and challenges are perceived meaningful, worthy and overcoming. Sense of Coherence can be applied at both an individual and family level, with the latter called a Family Sense of Coherence (FSOC) [3]. As claimed by Antonovsky [2], general resistance recourses (GRR) are crucial in the development of FSOC. Factors as characteristics of the person, a group or an environment, which facilitate the handling of tensions, are included in GRR. Moreover, social support is one of the most important components of GRR. FSOC, as a resistant recourse in families facing life challenges, may be important to uncover vulnerable families. Instruments as the FSOC scale, validated in different countries, may be a tool to help public health nurses in clinical practice to uncover and assess families.

\subsection{Background}

Parents are essential to family life, and good parenting has the potential to promote health and well-being, and prevent ill health and social problems in subsequent generations [4]. In this study, "family" refers to a self-defined group of two or more individuals who may or may not be related by bloodlines or law, but who function in such a way that they consider themselves to be a family [5]. The family unit has changed over the last few decades [4], with more single-parent families and extended families. The family unit is comprised of individuals, but when one family member becomes impaired, it exerts an influence on all family members in one way or another [6].

Attention deficit hyperactivity disorder (ADHD) is a condition that is not usually classified as a disease, but instead as a disability with childhood onset that often persists into adulthood [7]. People with the disability are a heterogeneous group with varied impairments, having difficulties regarding the regulation of their emotions and activities, and maintaining attention and impulse control. Families with children with ADHD have many challenges to deal with, both in the family unit and in society at large [8] [9]. Family functioning is described as more of a strain than in other families [10] [11] [12]. Parents with their own ADHD report lower well-being than other parents [9]. 
Persons with a stronger SOC find life to be emotionally meaningful, helping to make sense to areas of life also giving strain, such as living in a family with a child with ADHD. Straining life situations in families are interpreted as challenges important enough to invest energy in- and devotion to. SOC can contribute to make stressors understandable, and straining life situations may strengthen SOC over time, understanding the stressors as manageable and a feeling of confidence in their own resources [13]. Manageability refers to how the family's resources are appropriate and that the family is aware of these resources. These resources can include friends, colleagues of the parents, neighbors, peers or personnel at school and in the health services. People with a stronger SOC are more willing to use and to have trust in people giving support [14]. The social orientation of SOC lies as resources to manage stressors, such as in family life [2]. A strong SOC may also play a role as a protective factor modifying the implications of ADHD symptoms in youth reported in a five-year follow-up study [15].

To measure SOC on an individual level, a 29-item scale was developed by Antonovsky [2]. This scale was adjusted to a short form, known as the 13-item scale. To further measure the family's global sense of coherence, Antonovsky and Sourani [3] developed the Family Sense of Coherence (FSOC) scale. The scale has been translated and validated in China [16] and Turkey [17] and has also been used in China [16], Israel [18], South-Africa [19] and Turkey [20].

To help avoid errors in measurements, the reliability and validity of a scale are important [21]. The reliability of the scale's stability can be measured with test-retest and homogeneity with internal consistency [21]. The internal consistency has previous been reported with Cronbach's alpha values of 0.80 [17], 0.83 [16] and 0.84 [18]. The construct validity with factor analysis of the Chinese version showed that FSOC consisted of a single global factor [16]. Construct validity also related to convergent validity [21], with a comparison of scales measuring related constructs, showed also a strong correlation between FSOC and the Family Assessment Device (FAD) [17], and SOC and Family and Marital Outcome Measures [16]. To measure construct validity, the known group technique can be used [21]. Families with children with ADHD are one of many groups facing challenges in family life with a member who has a chronic disease or disorder. When looking at the family as a system, in which the individuals interact and influence each other and when one family member becomes impaired, this will influence the entire family [6]. There is a need for tools, as for example FSOC to assess and evaluate families in strainful life situations. Because FSOC has not previously been translated and validated into Norwegian, there is a need for such a procedure.

\subsection{Aim}

The aim of this study was therefore to assess the reliability and validity of the translated Norwegian version of the Family Sense of Coherence scale (N-FSOC).

\section{Methods}

\subsection{Design and Sample}

This study had a cross-sectional design, which included two groups of parents. A ran- 
dom sample, 548 out of 1,964 members of an ADHD association in Norway (Group A), who was parents to a child with ADHD aged 15 years and younger, were invited to participate. The response rate was $48.2 \%$, including 264 participants, 217 mothers and 47 fathers (mothers $82.2 \%$, fathers $17.8 \%$ ). A random sample, 583 out of 789 parents to children aged 12 to 15 years (Group B) from three schools in rural and urban municipalities, were invited to participate. The response rate was $26.9 \%$, including 157 participants, 106 mothers and 51 fathers (mothers 67.5\%, fathers 32.5\%).

\subsection{Ethical Considerations}

The study was approved by an ethical committee for medical and health research (ref. number: 2012/955/REK) and the Norwegian Social Science Data Service (ref. number: 42,756). The study was performed according to the Helsinki Declaration and the ethical research principles: confidentiality, non-maleficence and justice, were followed during the entire research process [22]. Parents of children who have ADHD may be a vulnerable group, and the families' sense of coherence can be a sensitive topic. On the other hand, it is important to include these families in research, thereby giving them the opportunity to be heard.

\subsection{Data Collection}

A randomized sample from the member list of an ADHD association-group A, was drawn. An employee at the association had the coding key and sent the questionnaire with an information letter by postal mail to the sample, and two reminders were sent. Group B-the researcher contacted the leader of schools and received lists of parents. The parents were sent the questionnaire with an information letter by postal mail and one reminder was sent. The FSOC was sent eight weeks later to 100 parents from group $B$, with a response rate of $52 \%$.

\subsection{Measures and Instruments}

The questionnaire included questions regarding the parents' background and characteristics of the children, and four instruments.

Parents' background included questions regarding age, gender, marital status (cohabitant/married or single/divorced/widow/widower), education (compulsory school, upper secondary school or college/university) and place of residence (urban or rural). Occupation and economic status were not included.

Characteristics of the child included age and gender.

The Family Sense of Coherence scale (FSOC) was constructed by Sagy and Antonovsky [23], with 26 items based on assessing a family orientation on the three components of comprehensibility, manageability and meaningfulness. This scale was later modified by Sagy and Antonovsky [23] to a 12-item scale. The scale measures the family's global SOC, rated on a seven-point scale with the anchors defined. Some examples of the items are: "To what extent do you have the feeling that you can influence what happens in your family?" and "Do you have the feeling that you are being treated un- 
fairly by your family?" A total scale score was computed by adding all the items together ranging from 12 to 87, with higher scores denoting a strong sense of family coherence. Permission for the translation and adaption of the Family Sense of Coherence to Norwegian was granted from Dr. S. Sagy, Ben-Gurion University of the Negev, Israel.

The Sense of Coherence scale-13 (SOC-13) was developed by Antonovsky [2]. This version consists of 13 items rated on a seven-point scale with the anchors defined. Some examples of items are: "How often has it happened that people whom you have counted on have disappointed you?" and "How often do you have the feeling that there is little meaning in the things you do in daily life?" A total scale score was computed by adding all the items together ranging from 13 to 91, with higher scores denoting a stronger sense of coherence.

The Family Assessment Device (FAD) was investigated with the subscale "General Functioning", which was developed by Epstein, Baldwin and Bishop [24], and measures the general family climate and functioning. The subscale consists of 12 statements rated on a four-point scale from 1 (totally agree) to 4 (do not agree at all), including six statements regarding healthy family functioning, such as "We can express feelings to each other" and six statements regarding unhealthy family functioning, such as "Making decisions is a problem for our family". A mean score for the scale was computed, with the lower mean score, the better the family functioning.

Well-being (Well) was developed by Sørensen, Bøe, Ingebrigtsen and Sandanger [25], and measures the degree of happiness, satisfaction, and how rewarding or unsuccessful life is perceived to be, including the Cantril ladder [26]. The instrument consists of four items, including "Would you say that you live a happy life at the moment?", "When you think of how you are currently, are you most satisfied or dissatisfied?" and "Would you say that your life is mostly filled with disappointments, or mostly encouragements?" The items are answered on a seven-point scale. The Cantril ladder contains one question: "Here is a ladder with 10 steps. If we think that the highest step on this ladder stands for the best life you could think of and the lowest the worst, what step would you say suits you in your present life?", which was answered using a 10-point scale. A mean score of the instrument was calculated by adding all the items, with the Cantril ladder multiplied by 7 and divided by 10 , before adding the three other items, with the higher score the better.

\section{Translation of the FSOC}

The English version of the FSOC [23] was translated into Norwegian with elements from Brislin [27]. The instrument was forward translated by a bilingual (English and Norwegian) health professional from the original English version. The health professional had the knowledge of the culture and content of the instrument. The Norwegian version was reviewed for incomprehensive or ambiguous wording. A panel of $20 \mathrm{ex}-$ perts in health care gave their comments regarding the clarity of the instrument, and some formulations were clarified by making them more understandable in a Norwegian setting. The back-translation into English was made by another bilingual health professional (Norwegian and English) who was "blinded" to the original English version. The 
research team reviewed the back-translated version with the original English version. The back-translation resulted in a highly similar version. Items with apparent discrepancies were examined to ensure that the content was the same. The instrument was pilot tested with 20 parents of children with ADHD. They gave their comments regarding clarity, and no further adjustments were made.

\subsection{Statistical Analysis}

Statistical analysis were performed using IBM statistics SPSS, version 22. T-tests were used to compare the two groups of parents with regard to background data (gender and age). Chi-square tests were used to compare the two groups regarding marital status, education and place of residence [28]. The internal consistency of the N-FSOC was assessed by Cronbach's alpha coefficients, with a Cronbach's alpha greater than 0.70 considered acceptable [29]. The questionnaire was analyzed for stability by the test-retest with the parents in group B, and two responses to the questionnaire were compared using the intraclass correlation coefficient (ICC) [30]. An ICC above 0.40 is acceptable, above 0.60 or greater indicates satisfactory stability, and greater than 0.80 is excellent [31].

The construct validity was assessed by the use of the "known-group technique" [21] using an independent samples t-test to compare the differences between the two group of parents. Based on previous studies, it was assumed that parents with a child with ADHD had a more difficult life situation, thereby reporting a lower score on FSOC than the other group of parents [9] [12]. The construct validity, convergent validity, of the scale was also tested by calculating the Pearson's correlation coefficient of N-FSOC with SOC, FAD and Well.

\section{Results}

The parents' background and the child's characteristics are reported in Table 1. There were statistically significant differences between the two groups of parents with regard to age, education and place of residence. The parents in group A was younger than those in group $\mathrm{B}(\mathrm{t}=7.68, p<0.001)$, whereas more parents in group B had a college/ university degree $\left(x^{2}=15.90, p<0.001\right)$, and lived in more urban areas $\left(x^{2}=18.40, p<\right.$ $0.001)$.

\subsection{Reliability}

The internal consistency using a Cronbach's alpha for the entire group was 0.89 , for group A 0.87 and group B 0.89 . The test-retest of group B $(\mathrm{n}=52)$, using intraclass correlation coefficient (ICC), was .85 (CI 0.73 - 0.91).

\subsection{Validity}

The construct validity with known groups (Polit \& Beck, 2012) revealed statistically significant differences between group $\mathrm{A}$ and group $\mathrm{B}$, in that the parents with a child having ADHD reported lower scores in N-FSOC, SOC, FAD and Well (Table 2). 
Table 1. Background data of the participants.

\begin{tabular}{|c|c|c|}
\hline & Group $A^{a} n(\%)$ & Group $B^{b} \mathrm{n}(\%)$ \\
\hline \multicolumn{3}{|l|}{ Background of the parents } \\
\hline Mothers & $217(82.20)$ & $106(67.50)$ \\
\hline Fathers & $47(17.80)$ & $51(32.50)$ \\
\hline Age-mean (SD) & $41.55(5.96)$ & $46.03(5.51)$ \\
\hline \multicolumn{3}{|l|}{ Marital status } \\
\hline Cohabitants/married & $223(84.50)$ & $129(82.20)$ \\
\hline Single/divorced/widow/widower & $41(15.50)$ & $27(17.20)$ \\
\hline \multicolumn{3}{|l|}{ Education } \\
\hline Compulsory/upper secondary school & $126(48.50)$ & $45(28.70)$ \\
\hline College/university & $134(50.80)$ & $111(70.70)$ \\
\hline \multicolumn{3}{|l|}{ Place of residence } \\
\hline Rural & $132(50)$ & $45(28.7)$ \\
\hline Urban & $132(50)$ & $112(71.30)$ \\
\hline \multicolumn{3}{|l|}{ The children } \\
\hline Age-mean (SD) & $12.17(2.24)$ & $13.92(0.84)$ \\
\hline \multicolumn{3}{|l|}{ Gender } \\
\hline Boy & $182(70.50)$ & $72(45.90)$ \\
\hline Girl & $76(29.50)$ & $85(54.10)$ \\
\hline
\end{tabular}

${ }^{\mathrm{a} G r o u p ~ A: ~ P a r e n t s ~ o f ~ c h i l d r e n ~ h a v i n g ~ A D H D ; ~}{ }^{\mathrm{b}}$ Group B: Parents of children aged 12 - 15 years.

Table 2. Comparing parents of children having ADHD with other parents.

\begin{tabular}{rcccc}
\hline & Group A n $=260 \mathrm{M}(\mathrm{SD})$ & Group B $\mathrm{n}=156 \mathrm{M}(\mathrm{SD})$ & $t^{\mathrm{a}}$ & $p$ \\
\hline FSOC $^{\mathrm{b}}$ & $57.88(10.86)$ & $66.37(9.68)$ & 8.26 & 0.001 \\
SOC $^{\mathrm{c}}$ & $62.85(10.91)$ & $69.50(9.14)$ & 6.65 & 0.001 \\
FAD $^{\mathrm{d}}$ & $1.98(0.52)$ & $1.65(0.39)$ & 7.47 & 0.001 \\
Well $^{\mathrm{e}}$ & $4.88(0.92)$ & $5.56(0.78)$ & 8.11 & 0.001 \\
\hline
\end{tabular}

${ }^{a}$ Independent-sample t-test; ${ }^{b}$ Family Sense of Coherence, sum scores could range from 12 (weakest) to 84 (strongest); 'Sense of Coherence, sum scores could range from 13 (weakest) to 91 (strongest); ${ }^{\mathrm{d} F a m i l y}$ Assessment Device, scores

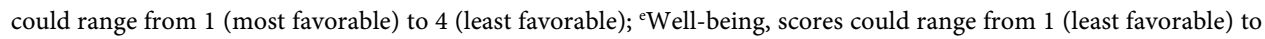
7 (most favorable).

The construct validity, with convergent validity, yielded the expected results that N-FSOC correlated positively with SOC and Well and negatively with FAD (Table 3).

\section{Discussion}

In this study, FSOC was translated into Norwegian, and analyzed for validity and reliability. The translation process was rigorous with regard to the use of back-translation technique [21], review of the translated questionnaire by an expert group and a pilot test with a group that corresponds with the target group for the study, responding to 
Table 3. Correlations of FSOC with FAD, SOC and well.

\begin{tabular}{ccccc}
\hline & & FAD $^{\mathrm{b}}$ & SOC $^{\mathrm{c}}$ & Well $^{\mathrm{d}}$ \\
\hline FSOC $^{\mathrm{a}}$ & Pearson Correlation & $-0.767^{* *}$ & $0.746^{\star *}$ & $0.764^{* *}$ \\
& Sig. (2-tailed) & 0.001 & 0.001 & 0.001 \\
$\mathrm{~N}$ & 416 & 410 & 415 \\
\hline
\end{tabular}

${ }^{a}$ Family Sense of Coherence, sum scores could range from 12 (weakest) to 84 (strongest); ${ }^{b}$ Family Assessment Device, scores could range from 1 (most favorable) to 4 (least favorable); 'Sense of Coherence, sum scores could range from 13 (weakest) to 91 (strongest); ${ }^{\mathrm{d}}$ Well-being, scores could range from 1 (least favorable) to 7 (most favorable). ${ }^{* *}$ Correlation is significant at the 0.01 level (2-tailed).

face validity [21]. After the translation process, two groups of parents, including both mothers and fathers, responded to the questionnaire. The two groups of parents were regarded to be appropriate because they were possible to compare on the basis that one group represents parents with a more difficult situation than the other.

Reliability was tested for internal consistency and stability [21]. Cronbach's alpha coefficients were above .80 for both the entire group and for the two groups of parents, thus indicating a sufficient internal consistency [29]. The alpha values were over .80, which is in line with other studies [16] [18]. The stability of the instrument analyzed with test-retest was found to be excellent, with an ICC value over 0.80 [31] in the group of 52 parents (group B), who responded twice on the N-FSOC over an eight-week period. In the study by Ngai and Ngu [16], the ICC was slightly lower, but still over 0.70 , thereby indicating a satisfactory stability.

Construct validity was assessed by correlations between N-FSOC and SOC, FAD and Well. N-FSOC exhibited a strong positive correlation with SOC, which was expected since both the individual-and family sense of coherence have been found to be related to each other [16] [18]. Well-being, which can be seen as a part of quality of life, demonstrated a positive correlation with FSOC. Other studies suggest FSOC as a resource against stress leading to a high quality of life [32] [33]. Additionally, FSOC serving as a mediator between stressful life events and quality of life is well suited with the salutogenic framework [34]. The high negative association between N-FSOC and FAD indicates that the stronger the FSOC the better family functioning, which is also supported in other studies [3] [17]; this is in line with a longitudinal study by Ngai and Ngu [33], who followed couples during pregnancy and after birth.

Furthermore, the assumption that the two groups of parents would differ (knowngroups) on FSOC, SOC, FAD and Well was achieved. The parents with a child with ADHD reported a weaker FSOC and SOC, a less favorable family functioning and a lower well-being, also supported by other studies [10] [12]. A previous study reported a consensus between mothers and fathers in FSOC, which suggests there is a collective family measure [33]. Families with a strong sense of coherence may have a more positive appraisal of the life situation that views demands in parenthood as a challenge. On the other hand, families with a child with ADHD face challenges not comparable to the situation of the average teenage family, as shown in this study's results. The parents in group A had significantly weaker FSOC and FAD than parents in group B. Having a strong global sense of coherence in the family may help facilitate family functioning, as 
shown by the correlation with FAD.

Some limitations of the present study have to be noted. Because only one of the family members responded to the questionnaire, the results reflect the family situation from the parent's perspective. In further studies, it is therefore important to include more family members. The response rate was low, particularly in group B. In general, there is a trend towards a declining survey response rates in many countries [35]. Another explanation may be that the questions were perceived as sensitive, resulting in some parents choosing not to respond. As the parents in the ADHD association were recruited via the association, they were probably more motivated to answer. However, few fathers in group A answered, and it has been found that mothers seem to be more involved and engaged than fathers in their child with ADHD (e.g. [36]). Moreover, another limitation is the significant differences between the groups. The parents in group B were older and over two-thirds had attained the college/university educational level and lived in urban areas. The differences can be explained by the different ways the two groups of parents were recruited. It was a nationwide recruitment in terms of parents from the ADHD association, whereas the parents in group B only represented three municipalities. Both groups may therefore reflect an elite bias with the high educational level in group B and the belonging to an association in group A. According to the validity and reliability testing of the N-FSOC, it was assumed that the groups should differ in their responses to N-FSOC, SOC, FAD and Well. Nevertheless, more studies including other groups to further assess the N-FSOC are needed.

\section{Conclusion}

The results of this study indicate that the Norwegian version of N-FSOC showed a sufficient validity and reliability in two groups of parents. Despite the satisfactory results, further studies are required with other samples and age groups to confirm the validity and reliability of N-FSOC. It is especially important to include families with more than one family member responding to the questionnaire.

\section{Relevance to Clinical Practice}

Nurses, other health-care professionals and researchers need valid tools to assess families in strainful life situations. Hence, N-FSOC may be appropriate as a tool to find families who seem to be vulnerable to help further facilitate interventions that strengthen the family's resources. Furthermore, researchers and health-care professionals need valid instruments to compare outcomes of interventions in both clinical practice and research. The FSOC has been used in several countries and been shown to be valid and reliable, including in Norway. N-FSOC may also be used regarding families in difficult life situations in relation to the family's global sense of coherence.

\section{Acknowledgements}

We want to thank Jari Appelgren. Statistician, for valuable discussions concerning statistical analysis. 


\section{References}

[1] Moen, Ø.L., Hedelin, B. and Hall-Lord, M.L. (2014) Public Health Nurses' Conceptions of Their Role Related to Families with a Child Having Attention-Deficit/Hyperactivity Disorder. Scandinavian Journal of Caring Sciences, 28, 515-522. https://doi.org/10.1111/scs.12076

[2] Antonovsky, A. (1987) Unraveling the Mystery of Health: How People Manage Stress and Stay Well. Jossey-Bass, San Francisco.

[3] Antonovsky, A. and Sourani, T. (1988) Family Sense of Coherence and Family Adaptation. Journal of Marriage and the Family, 50, 79-92. https://doi.org/10.2307/352429

[4] Gage, J., Everett, K. and Bullock, L. (2006) Integrative Review of Parenting in Nursing Research. Journal of Nursing Scholarship, 38, 56-62. https://doi.org/10.1111/j.1547-5069.2006.00078.x

[5] Whall, A. (1986) The Family as the Unit of Care in Nursing: A Historical Review. Public Health Nursing, 3, 240-249. https://doi.org/10.1111/j.1525-1446.1986.tb00495.x

[6] Wright, L.M. and Leahey, M. (2009) Nurses and Families: A Guide to Family Assessment and Intervention. F.A. Davis, Philadelphia.

[7] Barkley, R.A. (2006) Attention-Deficit Hyperactivity Disorder: A Handbook for Diagnosis and Treatment. Guilford Press, New York.

[8] Moen, Ø.L., Hall-Lord, M.L. and Hedelin, B. (2014) Living in a Family with a Child with Attention Deficit Hyperactivity Disorder: A Phenomenographic Study. Journal of Clinical Nursing, 23, 3166-3176. https://doi.org/10.1111/jocn.12559

[9] Moen, Ø.L., Hedelin, B. and Hall-Lord, M.L. (2016) Family Functioning, Psychological Distress, and Well-Being in Parents with a Child Having ADHD. SAGE Open, 6. https://doi.org/10.1177/2158244015626767

[10] Cussen, A., Sciberras, E., Ukoumunne, O. and Efron, D. (2012) Relationship between Symptoms of Attention-Deficit/Hyperactivity Disorder and Family Functioning: A Community-Based Study. European Journal of Pediatrics, 171, 271-280. https://doi.org/10.1007/s00431-011-1524-4

[11] Foley, M. (2011) A Comparison of Family Adversity and Family Dysfunction in Families of Children with Attention Deficit Hyperactivity Disorder (ADHD) and Families of Children without ADHD. Journal for Specialists in Pediatric Nursing, 16, 39-49. https://doi.org/10.1111/j.1744-6155.2010.00269.x

[12] Sollie, H., Mørch, W.-T. and Larsson, B. (2016) Parent and Family Characteristics and Their Associates in a Follow-Up of Outpatient Children with ADHD. Journal of Child and Family Studies, 25, 2571-2584.

[13] Olsson, M.B. and Hwang, C.P. (2002) Sense of Coherence in Parents of Children with Different Developmental Disabilities. Journal of Intellectual Disability Research, 46, 548-559. https://doi.org/10.1046/j.1365-2788.2002.00414.x

[14] Sørensen, T., Kleiner, R., Ngo, P., Sørensen, A. and Bøe, N. (2013) From Sociocultural Disintegration to Community Connectedness Dimensions of Local Community Concepts and Their Effects on Psychological Health of Its Residents. Psychiatry Journal, 2013, Article ID: 872146. https://doi.org/10.1155/2013/872146

[15] Edbom, T., Malmberg, K., Lichtenstein, P., Granlund, M. and Larsson, J.O. (2010) High Sense of Coherence in Adolescence Is a Protective Factor in the Longitudinal Development of ADHD Symptoms. Scandinavian Journal of Caring Sciences, 24, 541-547. https://doi.org/10.1111/j.1471-6712.2009.00746.x 
[16] Ngai, F.-W. and Ngu, S.-F. (2011) Translation and Validation of a Chinese Version of the Family Sense of Coherence Scale in Chinese Childbearing Families. Nursing research, 60, 295-301. https://doi.org/10.1097/NNR.0b013e3182269b00

[17] Cecen, A.R. (2007) The Turkish Version of the Family Sense of Coherence Scale-Short Form (FSOC-S): Initial Development and Validation. Educational Sciences. Theory \& Practice, 7, 1211-1218.

[18] Sagy, S. and Braun-Lewensohn, O. (2009) Adolescents under Rocket Fire: When Are Coping Resources Significant in Reducing Emotional Distress? Global Health Promotion, 16, 515. https://doi.org/10.1177/1757975909348125

[19] Greeff, A.P., Vansteenwegen, A. and Ide, M. (2006) Resiliency in Families with a Member with a Psychological Disorder. American Journal of Family Therapy, 34, 285-300. https://doi.org/10.1080/01926180600637465

[20] Kulik, L. (2008) Explaining the Sense of Family Coherence among Adolescents. International Journal of Child \& Family Welfare, 2, 97-110.

[21] Polit, D.F. and Beck, C.T. (2012) Nursing Research: Generating and Assessing Evidence for Nursing Practice. Wolters Kluwer Health, Philadelphia.

[22] Northern Nurses' Federation (2003) Ethical Guidelines for Nursing Research in the Nordic Countries. Northern Nurses' Federation, Oslo.

[23] Sagy, S. and Antonovsky, A. (1992) The Family Sense of Coherence and the Retirement Transition. Journal of Marriage and the Family, 54, 983-993.

https://doi.org/10.2307/353177

[24] Epstein, N.B., Baldwin, L.M. and Bishop, D.S. (1983) The McMaster Family Assessment Device. Journal of Marital and Family Therapy, 9, 171-180. https://doi.org/10.1111/j.1752-0606.1983.tb01497.x

[25] Sørensen, T., Bøe, N., Ingebrigtsen, G. and Sandanger, I. (1996) Individual-Local Community and Mental Health: Towards a Comprehensive Community Psychiatric Model for Prevention of Mental Problems and Promotion of Mental Health. Nordic Journal of Psychiatry, 50, 11-19. https://doi.org/10.3109/08039489609099726

[26] Cantril, H. (1966) The Pattern of Human Concerns. Rutgers University Press, New Brunswick.

[27] Brislin, R. (1970) Back-Translation for Cross-Cultural Research. Journal of Cross-Cultural Psychology, 1, 185-216. https://doi.org/10.1177/135910457000100301

[28] Field, A. (2013) Discovering Statistics Using IBM SPSS Statistics: And Sex and Drugs and Rock “n” Roll. SAGE, Los Angeles.

[29] Streiner, D.L. and Norman, G.R. (2008) Health Measurement Scales: A Practical Guide to Their Development and Use. Oxford University Press, Oxford. https://doi.org/10.1093/acprof:oso/9780199231881.001.0001

[30] Shrout, P.E. and Fleiss, J.L. (1979) Intraclass Correlations: Uses in Assessing Rater Reliability. Psychological Bulletin, 86, 420-428. https://doi.org/10.1037/0033-2909.86.2.420

[31] Landis, J.R. and Koch, G.G. (1977) An Application of Hierarchical Kappa-Type Statistics in the Assessment of Majority Agreement among Multiple Observers. Biometrics, 33, 363-374. https://doi.org/10.2307/2529786

[32] Eriksson, M. and Lindström, B. (2005) Validity of Antonovsky's Sense of Coherence Scale: A Systematic Review. Journal of Epidemiology and Community Health, 59, 460-466. https://doi.org/10.1136/jech.2003.018085

[33] Ngai, F.-W. and Ngu, S.-F. (2013) Family Sense of Coherence and Quality of Life. Quality 
of Life Research, 22, 2031-2039. https://doi.org/10.1007/s11136-012-0336-y

[34] Richardson, C.G. and Ratner, P.A. (2005) Sense of Coherence as a Moderator of the Effects of Stressful Life Events on Health. Journal of Epidemiology \& Community Health, 59, 979984. https://doi.org/10.1136/jech.2005.036756

[35] Tolonen, H., Helakorpi, S., Talala, K., Helasoja, V., Martelin, T. and Prättälä, R. (2006) 25-Year Trends and Socio-Demographic Differences in Response Rates: Finnish Adult Health Behaviour Survey. European Journal of Epidemiology, 21, 409-415. https://doi.org/10.1007/s10654-006-9019-8

[36] Fabiano, G. (2007) Father Participation in Behavioral Parent Training for ADHD: Review and Recommendations for Increasing Inclusion and Engagement. Journal of Family Psychology, 21, 683-693. https://doi.org/10.1037/0893-3200.21.4.683

\section{Submit or recommend next manuscript to SCIRP and we will provide best service for you:}

Accepting pre-submission inquiries through Email, Facebook, LinkedIn, Twitter, etc. A wide selection of journals (inclusive of 9 subjects, more than 200 journals)

Providing 24-hour high-quality service

User-friendly online submission system

Fair and swift peer-review system

Efficient typesetting and proofreading procedure

Display of the result of downloads and visits, as well as the number of cited articles

Maximum dissemination of your research work

Submit your manuscript at: http://papersubmission.scirp.org/

Or contact ojn@scirp.org 